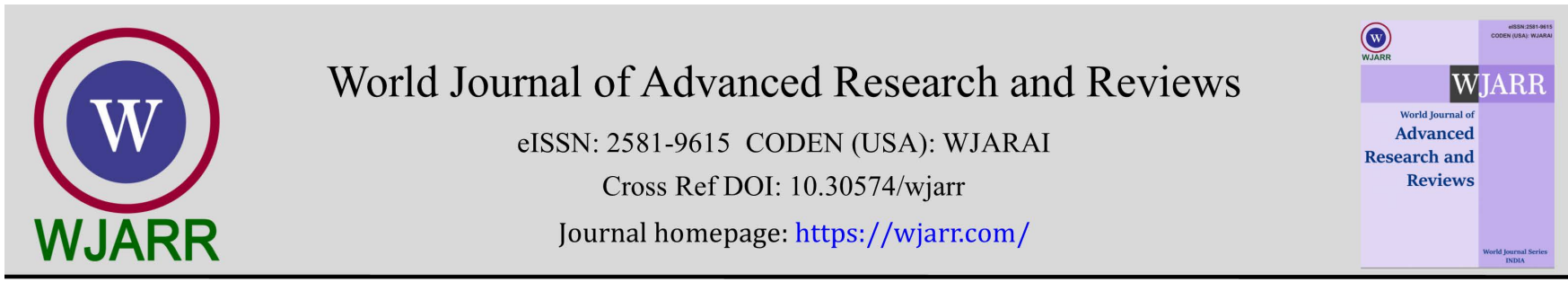

(RESEARCh ARTICLE)

Check for updates

\title{
Biochemical profile and resistance phenotype of bacteria isolated from the operating site departments of the National Reference University Hospital of N’Djamena
}

Bessimbaye Nadlaou 1, 2, *, Djimadoum Mbanga 2, Issakou Bakarnga-Via 2, Claude Oualé 2, Nicolas Barro ${ }^{3}$, Abdelsalam Tidjani ${ }^{2}$ and Choua Ouchemi ${ }^{1,2}$

${ }^{1}$ Biologist, Head of the Research and Training Unit (URF) and Head of Department, Laboratories of the National Reference University Hospital (CHU-RN) of N'Djamena. Centre Hospitalier Universitaire de Référence Nationale (CHU-RN) de N'Djamena (Chad).

${ }^{2}$ Faculty of Human Health Sciences (FSSH), University of N'Djamena, BP 1117 N'Djamena, Chad.

${ }^{3}$ Laboratory of Molecular Biology, Epidemiology and Surveillance of Bacteria and Viruses Transmitted by Food(LaBESTA)

/ Doctoral School of Sciences and Technologies, University of Ouaga 1 Joseph KI-ZERBO, 03 BP 7021 Ouagadougou 03,

Burkina Faso.

World Journal of Advanced Research and Reviews, 2021, 10(01), 381-396

Publication history: Received on 23 March 2021; revised on 28 April 2021; accepted on 30 April 2021

Article DOI: https://doi.org/10.30574/wjarr.2021.10.1.0189

\begin{abstract}
The aim is to assess the level of contamination of wound bacteria in operated patients in the surgical departments of the National Reference University Hospital (CHURN) of N'Djamena.

From August 1, 2018 to August 1, 2019, an observational culture study on wound pus was carried out in patients operated on from the surgical services of the N'Djamena CHURN according to standard methods of medical microbiology.

Of the 1092 patients operated on, 565 patients were released within a normal period of hospitalization and 527 in contact with the pathogens were maintained. Significant differences were observed between the proportions of positive $(86 \%)$ and sterile (14\%) cultures; female (30.36\%) and male (69.63\%) operated subjects with probabilities of 0.02 and 0.001 respectively.
\end{abstract}

Escherichia coli were the most common germs (32.7\%), followed by Staphylococcus spp (20.9\%). The bacteria isolated were resistant to beta-lactam antibiotics at an average rate of $40 \%$, only imipenem, a last-resort antibiotic, was very sensitive (99.5\%).

In view of these results, we recommend that prescribers avoid prescribing antibiotics without laboratory evidence for fear of losing the beta-lactams permanently.

Keywords: Infection; Surgical site, Antibiotic; Resistance; N’Djamena.

\footnotetext{
* Corresponding author: Nadlaou Bessimbaye

Lecturer/Master Assistant, Faculty of Human Health Sciences (FSSH), University of N'Djamena, BP 1117 N'Djamena, Chad.

Copyright $(2021$ Author(s) retain the copyright of this article. This article is published under the terms of the Creative Commons Attribution Liscense 4.0.
} 


\section{Introduction}

Surgical Site Infections (SSI) are hospital infections. They are related to the pre and / or post-operative elements. The term "SSI" replaces that of surgical wound infection [17].

ISO is defined by the presence of pus from a wound in the following locations:

- $\quad$ Superficial part of the surgical incision (skin and subcutaneous tissue);

- Deep part of the surgical incision (soft tissue, deep below the fascia);

- Cavity or organ near or far from the surgical site but linked to the procedure. $[17,6]$.

An SSI is considered nosocomial when it is neither present nor incubating on entry; it occurs within 30 days of the operation. This period is extended to one year in the event of placement of artificial prosthetic material [6]. Nosocomial infections are a worrying public health problem due to their frequency, cost and severity. The World Health Organization (WHO) estimates that an average of 190 million people is hospitalized each year worldwide and that 9 million of them contract a nosocomial infection during this time [6].

Statistics relating to the frequency of postoperative infections rank that of the operative site second after urinary tract infections [2]. They are the leading cause of morbidity and mortality in surgery [3].

In France, in 2004, the number of people operated on was estimated at 6 million per year and 2 to $3 \%$ of them developed an ISO. This rate is confirmed by the result of the common database (RAISAIN) of the 5 investigation and surveillance networks for the fight against nosocomial infections (CCLIN): In 1998 and 1999, on three types of interventions combined, 2551 ISO were declared for 102228 acts [6].

ISO is the second most frequently reported type of nosocomial infection in the United States [14].

In sub-Saharan Africa the incidence of surgical site infections was 6.8 in Kenya, 11.4\% (Ethiopia), 23.6\% (Nigeria) and $26 \%$ in Tanzania [12].

In Chad, a survey carried out from January 28 to February 22018 at the N'Djamena National Reference HospitalUniversity Center (CHU-RN) reported that the prevalence of nosocomial infections was 16.8\% [23].

ISOs increase significantly and patient mortality is due to microorganisms for which the study of antibiotic sensitivity is essential to guide antibiotic therapy and improve management. It is with this in mind that our study, the objective of which was to assess the level of contamination of bacterial agents involved in the ISOs of the General Surgery, Urology and Traumatology departments of the CHU-RN, falls within this perspective.

\section{Material and methods}

\subsection{Framework, Type and period of study}

Our study took place in the bacteriology unit in the CHURN laboratory. The pus samples were taken in the General Surgery, Urology and Traumatology Departments of the said hospital.

This was a prospective observational study that took place in N'Djamena over a period from August 01, 2018 to August 01, 2019 at CHURN.

\subsection{Study population}

Our study concerned patients operated on and hospitalized during this period in the departments of General Surgery, Urology and Traumatology.

\subsection{Inclusion and non-inclusion criteria}

Were included in our study, patients who were operated on and hospitalized for at least 72 hours and who were in contact with ISOs from August 01, 2018 to August 01, 2019 in the General Surgery, Urology and Traumatology departments. 
Patients hospitalized in the departments concerned but not operated on and operated on and not having contact with the ISOs were excluded from our study.

\subsection{Collecting samples}

A search for SSIs was performed in 527 patients, aged 15 to 90 years, hospitalized in operative sites with informed consent.

Wound pus samples were collected in each hospital ward, by syringe puncture or by swabbing. The sample is then sent to the laboratory department with bulletins containing information about the patient (hospitalization department, last name, first name, age, sex, profession and address).

\subsection{Data processing}

Data was entered and analyzed using Microsoft Word and Excel 2013.

The chi-square test $\left(\chi^{2}\right)$ was used for the comparison of qualitative variables with a significance level set at 0,05.

\section{Microbiological analysis}

\subsection{Macroscopic examination of pus}

\subsubsection{Macroscopic examination of pus consisted of noting:}

- $\quad$ The smell of pus: foul, excrement;

- The consistency of the pus: liquid, thick or sticky;

- The color of the pus: yellow-green, red-brown, whitish or greenish;

- Microscopic examination.

- Microscopic examination was performed before and after the culture:

- The morphology of the germs isolated was studied on a smear stained with Gram;

- The study of cultural characteristics focused on the appearance and color of the colonies.

\subsection{Culture and antibiogram}

\subsubsection{Culture of bacteria}

It consisted of inoculating pathological products on culture media (Hektoen, chapman, chocolate agar) by the streak method. It is always done near the flame of a Bunsen burner and the boxes with inverted lids have been incubated in an oven at $37^{\circ} \mathrm{C}$ for 18 to 24 hours.

\subsubsection{Biochemical identification}

The test for catalase was carried out after isolation on Chapman's medium or 24-hour chocolate agar, a distinct colony is taken and placed on a slide, a drop of hydrogen peroxide $\mathrm{H}_{2} \mathrm{O}_{2}$ will be added to the colony.

Catalase is an enzyme that catalyzes the breakdown of hydrogen peroxide $\left(\mathrm{H}_{2} \mathrm{O}_{2}\right)$ into $\mathrm{H} 2 \mathrm{O}$ and $1 / 2 \mathrm{O}_{2}$ producing a foaming solution. Staphylococcus were tested catalase positive and Streptococcus catalase negative.

The coagulase search was carried out from a 24-hour culture on Chapman medium, a characteristic colony is suspended in physiological water, using a Pasteur pipette, $1 \mathrm{~mL}$ is transferred into $9 \mathrm{~mL}$ of (BHIB). At the end of an $18 \mathrm{~h}$ incubation at $37^{\circ} \mathrm{C}$, if the medium is cloudy, $0.5 \mathrm{~mL}$ of the latter is taken and $0.5 \mathrm{~mL}$ of human plasma is added and placed in an oven at $37^{\circ} \mathrm{C}$. The plasma coagulation is observed every $3 \mathrm{~min}$ and then after 30 minutes, 1 hour, $2 \mathrm{~h}, 4 \mathrm{~h}$ and $6 \mathrm{~h}$.

Oxidase test: the oxidase test is done on a fresh colony from Mueller-Hinton agar. In practice, a colony of germs to be studied is taken with the taper of a Pasteur pipette or a platinum loop, and it is crushed on a filter paper impregnated with a $1 \%$ solution of tetramethyl-para. phenylene diamine. Oxidase negative organisms will remain colorless and positive, turning purple after 10 seconds. Stains appearing beyond this time are not taken into account.

TDA (Tryptophan Deaminase) can also be detected in urea by adding 2 drops of TDA reagent, the spontaneous appearance of dark red brown color shows that TDA is positive. 
ONPG (Ortho Nitro Phenyl Galactosidase), the ONPG disc is deposited in a bacterial suspension of $1 \mathrm{~mL}$ of distilled water, the yellow color release in the suspension shows its use by bacteria and attests to the demonstration of Bêtagalactosidase.

To better identify the bacteria isolated during this study, API galleries were used. API galleries are systems for the identification of Gram-negative bacteria and Gram-negative bacteria using standardized and miniaturized biochemical tests, in microtubules in dehydrated form. The principle is based on the inoculum of microtubules with a bacterial suspension which rehydrates the media. Incubation is carried out at $37^{\circ} \mathrm{C}$ for 24 hours during which biochemical reactions take place (decarboxylation, fermentation, and deamination.) Which result in spontaneous colored products revealed by the addition of reagents.

The identification of bacteria is obtained using the API catalog. The catalog provides the identification of a large number of profiles obtained on API, which confers great reliability in the interpretation of the results.

The API 20 E galleries (Bio Mérieux) were used to characterize Enterobacteriaceae, Pseudomonas and the API STAPH and API STREP (Bio Mérieux) galleries, for the detection of Staphylococcus and Streptococcus.

\subsubsection{Antibiogram}

Two methods were used to perform the antibiogram: the manual method and the automated method with the Vitek Compact:

\subsubsection{Manual methods.}

This method, by diffusion, uses discs whose active principal load is variable according to the antibiotics tested. The antibiotics were deposited on an agar culture medium, inoculated by flooding or swabbing. The antibiotic diffuses into the agar creating a zone of inhibition of growth of the germ around the disc, depending on the diameter of this zone of inhibition the strains can be classified as sensitive (no growth), intermediate (growth in the well weakly dosed in antibiotic) or resistant (grows in both cups).

\subsubsection{Principle}

The principle of this consisted in placing paper discs impregnated with the different antibiotics tested on the agar surface of a Petri dish, each antibiotic diffuses into the agar and its concentration is found inversely proportional to the distance from the disc. It is a simple agar diffusion method using discs to determine the susceptibility of bacteria to antibiotics.

The bacteria were cultured on Muller Hinton agar (Bio Mérieux) for 18 to 24 hours so that they were in the exponential phase of growth. From this culture, a few colonies were picked and emulsified in sodium chloride saline solution $(0.9 \%$ $\mathrm{NaCl}$ ). The turbidity of the inoculum was measured with Densimat (Bio Mérieux) adjusted to 0.5 of the Mac Farland scale in accordance with the recommendations of the CA-SFM (2018). Tenth (1/10) dilutions of these suspensions were made in physiological water.

\subsubsection{Seeding}

The inoculation was carried out from a pure young strain of 18-to-24-hour culture, isolated on MH agar. The bacterial inoculum was diluted in a sterile $5 \mathrm{~mL}$ hemolysis tube. This inoculum was adjusted to an optical density of $0.5 \mathrm{Mc}$ Farland as recommended by CA-SFM 2018). Fifteen (15) minutes after adjustment, a swab was dipped into the inoculum. The soaked swab was pressed firmly against the bottom wall of the tube just above the level of the liquid while rotating it to remove the excess inoculum. This squeezed swab was rubbed three times on the agar surface, rotating the dish $60^{\circ}$ each time, after strongly. This is to achieve an even distribution of the inoculum. The inoculated dishes were left in the microbiological safety hood for 15 minutes before the application of the antibiotic discs.

\subsubsection{Choice of antibiotic discs}

We have selected a total of 18 antibiotics from different families (Beta-lactams, Sulfonamides-Trimethoprims, Cyclines, Aminoglycosides, Fusidic acid, Macrolides, Glycopeptides, Quinolones and Fluoroquinolones). Antibiotic discs tested include: penicillin (PEN: $10 \mathrm{IU}$ ), oxacillin (OXA: $5 \mu \mathrm{g}$ ), amoxicillin / clavulanic acid (AMC) (20/10 $\mu \mathrm{g})$, ceftriaxone (CRO) $(30 \mu \mathrm{g})$, amoxicillin (AMX) $(30 \mu \mathrm{g})$, ceftazidime (CAZ) $(30 \mu \mathrm{g})$, imipenem (IMP) (10 $\mu \mathrm{g})$, gentamicin (CN) (10 $\mu \mathrm{g})$, amikacin (AK) (30 $\mathrm{g})$, tobramycin (TOB) $(10 \mu \mathrm{g})$, nalidixic acid (NA) (30 $\mu \mathrm{g})$, ciprofloxacin (CIP) (5 $\mu \mathrm{g})$, ofloxacin (OFX) 
(5 $\mu \mathrm{g})$ and trimethoprim-sulfamethoxazole (SXT) $(1.25 / 23.75 \mu \mathrm{g})$, erythromycin (Ery) (15 IU), fusidic acid (FA) (10 $\mu \mathrm{g})$, tetracycline (TE) (30 IU), vancomycin (VA) (30 $\mu \mathrm{g})$.

\subsubsection{Disposal of antibiotic impregnated discs}

The discs are deposited firmly on the surface of the inoculated and dried agar. The number of discs deposited per box is limited due to the overlap of the zones of inhibition and to limit interference between the antibiotics. It is important that the diameters of the inhibition zones are measurable.

\subsection{Seven discs were placed for the $90 \mathrm{~mm}$ diameter boxes.}

\subsubsection{Incubation of Petri dishes}

The dishes were inverted within $15 \mathrm{~min}$ after depositing the discs and then incubated in a $37^{\circ} \mathrm{C}$ incubator for 18 to 24 hours. The stack of boxes in the oven was three boxes to avoid temperature differences related to the heating and ventilation system.

\subsubsection{Measurement of zones of inhibition and clinical categorization}

The border of the zone of inhibition was read with the naked eye and at the level of complete culture inhibition. Each diameter of the inhibition zones was read to the nearest millimeter using a graduated ruler. Clinical categorization was done in accordance with the recommendations of CASFM (2018) / EUCAST (2017). Intermediate category antibiotics were also counted as resistant.

\subsubsection{Detection of Extended Spectrum Beta Lactamase (ESBL) production}

The demonstration of ESBL was made on Muller-Hinton agar by the double disc synergy test method according to the procedure of Jarlier et al. (1988). The strains to be tested were inoculated on the agar by the standard antibiogram method. Cefotaxime $(30 \mu \mathrm{g})$, cefixime $(30 \mu \mathrm{g})$, cefoxitin $(30 \mu \mathrm{g})$, and vancomycin $(30 \mu \mathrm{g})$ discs were placed 20 to $30 \mathrm{~mm}$ (center to center) from an amoxicillin disc + clavulanic acid $(20 / 10 \mu \mathrm{g})$ then incubated at $35-37^{\circ} \mathrm{C}$. After 18 to 24 hours of incubation, the production of ESBL by the organism tested was based on the partial inhibition of ESBL by clavulanic acid. The existence of even a weak synergy between cefotaxime, cefixime, cefoxitin, vancomycin and clavulanic acid is characterized by a champagne cork-shaped image.

\subsubsection{Automated method (VITEK)}

The system consists of the VITEK ${ }^{\circ} 2$ Compact instrument, a computer (workstation) and a printer. The software supplied with the VITEK ${ }^{\circledR} 2$ Compact system includes programs for analysis and data management. A two-way computer interface automatically transfers results to the User's Laboratory Information System (LIS) and to various product and patient reports. A quality control system is available to validate a VITEK® 2 Compact System test kit. An Advanced Expert System ${ }^{\text {TM }}$ (AES) (clinical use) is available, in order to allow systematic and online validation of the results and an interpretation of the resistance phenotypes that have been demonstrated by the antibiograms.

\subsubsection{Principle}

This technique makes it possible to determine the sensitivity of bacterial agents to antibiotics in a semi-liquid medium. The VITEK $囚 2$ card includes 64 reaction cups comprising 64 antibiotics at 64 different concentrations. The reading is taken at $660 \mathrm{~nm}$. The growth rate analysis is performed every 15 minutes in kinetics. Then, for each antibiotic, a specific algorithm converts the raw values (RTU) into the calculated MIC. To calculate the MIC, the machine checks the filling of the wells, then checks the raw values. It eliminates raw outliers associated with background noise and difficult-tosuspend strains. Then, it determines the incubation time of the card. In the control cup, it evaluates the speed of growth of the germ. The reading will stop if there is sufficient growth in all wells. This will be considered the highest that can be measured for that antibiotic.

Finally, the MIC results are interpreted in S-I-R (sensitive-intermediate-resistant) according to the specific critical concentrations of the different committees.

Preparations of the inoculum for the isolation of bacterial agents were carried out according to the manufacturer's procedures and procedures. Using a dispenser, we distributed $3 \mathrm{~mL}$ of saline solution (Reference 1204, $500 \mathrm{~mL}$, Nacl $0.45 \%$ ) in the $5 \mathrm{~mL}$ tubes classified in a cassette. Then, using a Pasteur pipette, a colony of bacteria or yeasts was suspended in $3 \mathrm{~mL}$ of saline solution, well mixed and then the optical density was checked with DensiChek McFarland (0.5-0.63) McF for Gram (-) and Gram (+) bacteria. 
For each suspension, there is a biochemical and antibiogram identification. A Gram (-) V1 221 pipette $(0.5-250 \mu \mathrm{l})$ was used to distribute $145 \mu \mathrm{l}$ of identification suspension in $3 \mathrm{ml}$ of saline solution for antibiogram (GN $=$ Gram (-) and AST = corresponding antibiotic) for each identification. A Gram (+) V1 222 pipette (100-1000 $\mu \mathrm{l})$ was used to distribute 280 $\mu \mathrm{l}$ of identification suspension in $3 \mathrm{ml}$ of saline solution for antibiogram (GP = Gram ( + ) and AST = corresponding antibiotic) for each identification. The biochemical identification cards, antibiogram were inserted in the suspensions arranged in the cassette and the whole was introduced into the VITEK2. Once the cassette has been inserted into the VITEK2, we launch the loading and the Vitek2 reads the bar codes of each card and then the sealing. At the end of the sealing, we remove the identification cassette and the VITEK2 proceeds to analyzes. Vitek2 gives the minimum inhibitory concentration of antimicrobials according to the European Antibiotic Committee (CAEU).

\section{Results}

\subsection{Study population, laboratory and clinical parameters of patients}

The study concerned 527 patients, aged 15 to 90 years, including 367 (70\%) men or 3/4 and 160 (30\%) women followed in the various surgical departments (General Surgery, Urology and Traumatology).

The average age of the patients was 52.5 years with the extremes of 15 to 90 years and $43 \%$ of them belonged to the age group of 20 to 30 years.

\subsection{Prevalence of different germs isolated in pus}

Table 1 shows the distribution in number of cases of opportunistic microorganisms isolated from the pus of different surgical departments.

Of the 527 cultures performed, 453 cultures were positive (86\%) and $74(14 \%)$ sterile cultures $\left(\mathrm{x}^{2}=5.731\right.$ dof $=1, p=$ 0.02 significant difference for the positive culture).

\subsection{Distribution of germs by services}

Table 1 below shows the distribution of germs according to the services.

During the investigation, 425 (94\%) bacterial agents were identified with a predominance of Escherichia coli 139 (32.7\%) followed by Staphylococcus spp 89 (20.9\%).

Table 1 Distribution of germs according to services

\begin{tabular}{|l|l|l|l|l|l|}
\hline \multirow{2}{*}{ Bacterial agent } & \multirow{2}{*}{ GRAM } & \multicolumn{3}{|l|}{ Services } \\
\cline { 3 - 7 } & & NT (\%) & Visceral surgery & Urology & Traumatology \\
\hline Escherichia coli & BGN & $139(32.7)$ & 31 & 61 & 47 \\
\hline Staphylococcus spp & CGP & $89(20.9)$ & 24 & 38 & 27 \\
\hline Streptococcus spp & CGP & $52(12.3)$ & 13 & 24 & 15 \\
\hline Staphylococcus aureus & CGP & $51(12)$ & 14 & 19 & 18 \\
\hline Proteus spp & BGN & $23(5,5)$ & 5 & 11 & 7 \\
\hline Pseudomonas aeruginosa & BGN & $19(4,6)$ & 2 & 9 & 8 \\
\hline Proteus mirabilis & BGN & $16(3,8)$ & 3 & 7 & 6 \\
\hline Pseudomonas spp & BGN & $16(3,8)$ & 1 & 9 & 6 \\
\hline \multicolumn{7}{|l|}{ BGN = GRAM negative bacillus.; CGP GRAM positive Cocci; NT = Number tested; $\%=$ percentage } \\
\cline { 3 - 7 }
\end{tabular}

\subsection{Distribution of patients by sex}

Female subjects operated on were $30.36 \%(160 / 527)$ and $69.63 \%(367 / 527)$ patients were male $\left(x^{2}=22.031>x_{0}^{2}>\right.$ $3.84, p=0.001$, dof $=1$, significant difference in favor of the masculine gender). 
The male / female sex ratio is 2.29 (367/160) for operated subjects with positive cultures (Figure 1) and $3(819 / 273)$ for all operated subjects.

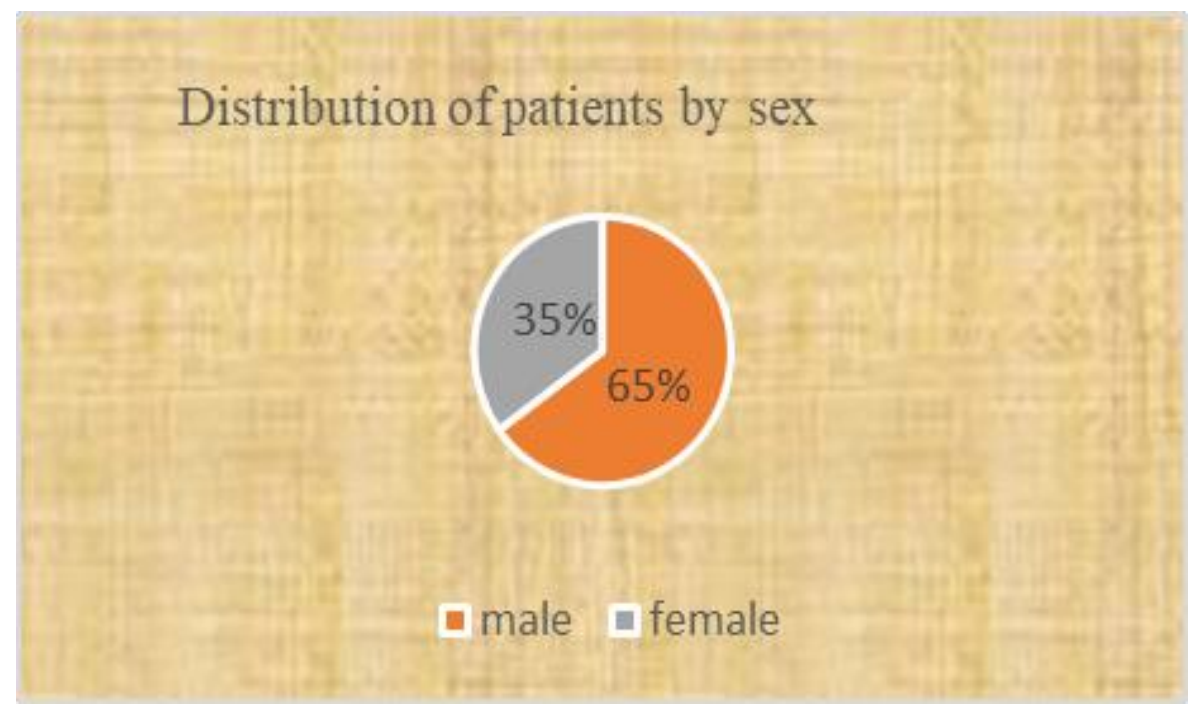

Figure 1 Distribution of patients by sex

\subsection{Distribution of patients by age group and sex}

The following figure shows the distribution of patients by age group and sex

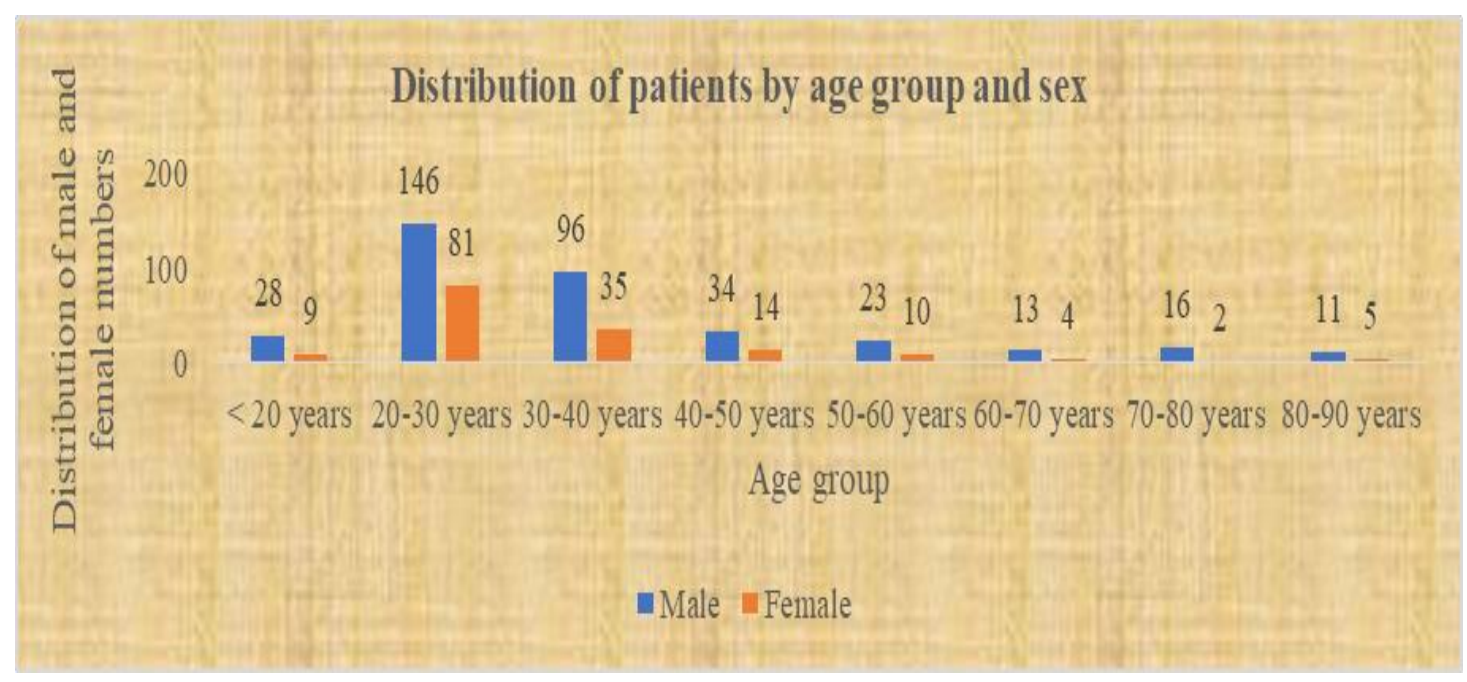

Figure 2 Distribution of patients by age group and sex

\subsection{Distribution of patients by profession}

Table 2 below shows the distribution of patients by profession. During our study, the most represented profession was that of pupils and students $146(27.8 \%)$. 
Table 2 Distribution of patients by profession

\begin{tabular}{|l|l|l|}
\hline Profession & Effective & $\mathbf{\%}$ \\
\hline Pupil / Student & 146 & 27.8 \\
\hline teamster & 82 & 15.7 \\
\hline Unemployed & 69 & 13.1 \\
\hline Housewife & 63 & 11.9 \\
\hline Functionary & 59 & 11.1 \\
\hline Trader & 59 & 11.2 \\
\hline Cultivator & 49 & 9.2 \\
\hline Total & $\mathbf{5 2 7}$ & $\mathbf{1 0 0}$ \\
\hline
\end{tabular}

\subsection{Distribution of patients according to the sampling site}

The abdomen was the most frequent harvest site with 284 (53.9\%) followed by the lower limbs (29.5\%).

Table 3 Distribution of patients according to the sampling site

\begin{tabular}{|l|l|l|}
\hline Sampling site & Number & $\mathbf{\%}$ \\
\hline Abdomen & 284 & 53.9 \\
\hline Trunk & 8 & 1.5 \\
\hline Upper members & 80 & 15.1 \\
\hline Legs & 155 & 29.5 \\
\hline Total & 527 & 100 \\
\hline
\end{tabular}

\subsection{Morphological characteristics of isolated bacteria}

After 24 hours of incubation, the Staphylococcus aureus degrading mannitol into lactic acid on Chapman, the modification of a $\mathrm{pH}$ indicator indicating the consumption of a sugar and the lowering of the $\mathrm{pH}$ causes the acidification of the medium and the appearance yellow in color. The whitish and greyish colonies in the same medium were characterized as groups of Staphylococcus spp.

Opaque yellow colonies in Hektoen medium were suspected to be Escherichia coli. In 24 to 48 hours, there is often a blue or greening of the culture media due to the diffusible pigments produced by the Pseudomonas colonies in the Hektoen medium. Grayish colonies in chocolate agar medium were suspected of Streptococcus.

\subsection{Assessment of the sensitivity of 11 antibiotics to bacteria isolated from ISOs}

Table 4 below shows the sensitivity of the 11 antibiotics to the different strains isolated during the investigation.

\subsection{Beta-lactam susceptibility profile of bacterial agents}

Table 4 below shows the distribution of the germs isolated according to their sensitivity to antibiotics.

\subsection{Biochemical profile of bacterial agents isolated from the carbohydrates tested}

Most of the isolated Staphylococci were: Catalase +, ADH (arginine hydrolase) +. All Staphylococcus aureus were coagulase positive. They ferment glucose and sucrose.

Most of the Escherichia coli identified were ONPG +, Indole + and fermented many sugars (carbohydrates).

The Pseudomonas isolated were oxidase +, possessing an oxidative type of carbohydrate metabolism or no action on sugars. 
Table 4 Sensitivity of Bacterial Agents to Beta-lactams

\begin{tabular}{|c|c|c|c|c|c|c|c|c|c|c|c|c|c|c|c|c|c|}
\hline \multirow[b]{3}{*}{ Bacterial agents } & \multirow[b]{3}{*}{ Nbre T } & \multicolumn{16}{|c|}{ Antibiotic } \\
\hline & & \multicolumn{2}{|c|}{ PEN } & \multicolumn{2}{|c|}{ OXA } & \multicolumn{2}{|c|}{ CAZ } & \multicolumn{2}{|c|}{ CRO } & \multicolumn{2}{|c|}{ AMX } & \multicolumn{2}{|c|}{ AMP } & \multicolumn{2}{|c|}{ AMC } & \multicolumn{2}{|c|}{ IMP } \\
\hline & & S & $\mathrm{R}$ & S & $\mathrm{R}$ & $\mathrm{S}$ & $\mathrm{R}$ & $S$ & $\mathrm{R}$ & S & $\mathrm{R}$ & S & $\mathrm{R}$ & $\mathrm{S}$ & $\mathrm{R}$ & S & $\mathrm{R}$ \\
\hline Staphylococcus aureus & 51 & 15 & 36 & 23 & 28 & 20 & 31 & 26 & 25 & 24 & 27 & 13 & 37 & 24 & 27 & 51 & 0 \\
\hline Staphylococcus spp & 89 & 30 & 59 & 28 & 61 & 27 & 52 & 46 & 43 & 49 & 40 & 58 & 31 & 60 & 29 & 88 & 1 \\
\hline Streptococcus agalactiae & 8 & 3 & 5 & 2 & 6 & 4 & 4 & 5 & 3 & 2 & 6 & 1 & 7 & 5 & 3 & 8 & 0 \\
\hline Streptococcus faecalis & 8 & 2 & 6 & 1 & 7 & 3 & 5 & 4 & 4 & 3 & 5 & 3 & 5 & 4 & 4 & 8 & 0 \\
\hline Streptococcus spp & 52 & 22 & 30 & 11 & 41 & 25 & 27 & 29 & 33 & 24 & 26 & 18 & 34 & 34 & 18 & 52 & 0 \\
\hline Escherichia coli & 139 & 37 & 102 & 41 & 98 & 52 & 87 & 79 & 60 & 75 & 64 & 39 & 100 & 89 & 50 & 139 & 0 \\
\hline Enterobacter cloacae & 4 & 1 & 3 & 2 & 2 & NT & NT & 3 & 1 & 2 & 2 & 1 & 3 & 2 & 2 & 4 & 0 \\
\hline Proteus mirabilis & 16 & 6 & 10 & 4 & 12 & 7 & 9 & 10 & 6 & NT & NT & 5 & 11 & 9 & 7 & 15 & 1 \\
\hline Proteus spp & 23 & 8 & 15 & NT & NT & NT & NT & 13 & 10 & 6 & 17 & 5 & 18 & 14 & 9 & 23 & 0 \\
\hline Pseudomonas spp & 16 & 5 & 11 & 3 & 13 & 10 & 6 & 7 & 9 & 6 & 10 & 5 & 11 & 7 & 9 & 16 & 0 \\
\hline Pseudomonas aeruginosa & 19 & 6 & 13 & NT & NT & 13 & 6 & 8 & 11 & 6 & 13 & 5 & 14 & 9 & 10 & 19 & 0 \\
\hline Total (\%) & $\begin{array}{l}25 \\
(100)\end{array}$ & $\begin{array}{l}135 \\
(31.7)\end{array}$ & $\begin{array}{l}290 \\
(68.2)\end{array}$ & $\begin{array}{l}115 \\
(27)\end{array}$ & $\begin{array}{l}268 \\
(63)\end{array}$ & $\begin{array}{l}161 \\
(37.8)\end{array}$ & $\begin{array}{l}227 \\
(53.4)\end{array}$ & $\begin{array}{l}230 \\
(54.1)\end{array}$ & $\begin{array}{l}205 \\
(48.2)\end{array}$ & $\begin{array}{l}197 \\
(46.3)\end{array}$ & $\begin{array}{l}210 \\
(49.4)\end{array}$ & $\begin{array}{l}153 \\
(36)\end{array}$ & $\begin{array}{l}271 \\
(63.7)\end{array}$ & $\begin{array}{l}257 \\
(60.4)\end{array}$ & $\begin{array}{l}168 \\
(39.5)\end{array}$ & $\begin{array}{l}423 \\
(99.5)\end{array}$ & $\begin{array}{l}2 \\
(0.4)\end{array}$ \\
\hline
\end{tabular}

PEN = penicillin; $\mathrm{OXA}$ = oxacillin; CAZ = ceftazidine; $\mathrm{CRO}$ = ceftriaxone; AMX = amoxicillin; AMP = ampicillin; AMC; amoxicillin + clavulanic acid; IMP = imipenem; Nbre T = total number. 
Table 5 Biochemical profile of bacterial agents isolated from pus in surgical site patients

\begin{tabular}{|c|c|c|c|c|c|c|c|c|c|c|c|c|c|c|c|c|c|c|c|c|c|c|c|c|}
\hline \multirow{2}{*}{$\begin{array}{l}\text { Bacterial } \\
\text { agent }\end{array}$} & \multicolumn{21}{|c|}{ Carbohydrate } & & & \\
\hline & ONPG & ADH & LDC & ODC & CIT & $\mathrm{H}_{2} \mathrm{~S}$ & URE & TDA & IND & VP & GEL & GLU & MAN & INO & SOR & RHA & SAC & MEL & AMY & ARA & $\mathrm{COA}$ & CAT & GAL & ox \\
\hline $\begin{array}{l}\text { Staphylococcus } \\
\text { aureus }\end{array}$ & & + & & & & & $+/-$ & & & + & & + & & & & & + & & & & + & + & & \\
\hline $\begin{array}{l}\text { Staphyloccocus } \\
\text { spp }\end{array}$ & & $+/-$ & & & & & $+/-$ & & & $+/-$ & & + & & & & & $+/-$ & & & & - & + & & \\
\hline $\begin{array}{l}\text { Streptoccocus } \\
\text { agalactae }\end{array}$ & & & & & & & & & & & $+/-$ & + & & & & & & & & & & - & - & \\
\hline $\begin{array}{l}\text { Streptoccocus } \\
\text { faecalis }\end{array}$ & & + & & & & & & & & & $+/-$ & + & & & + & & & & & - & & - & + & \\
\hline $\begin{array}{l}\text { Streptococcus } \\
\text { spp }\end{array}$ & & $+/-$ & & & & & & & & & & + & & & $+/-$ & & & & & $+/-$ & & - & $+/-$ & \\
\hline $\begin{array}{l}\text { Enterobacter } \\
\text { cloacae }\end{array}$ & + & - & - & - & + & - & $+/-$ & - & - & + & - & + & + & - & - & $+/-$ & - & - & $+/-$ & - & & + & & - \\
\hline $\begin{array}{l}\text { Proteus } \\
\text { mirabilis }\end{array}$ & - & - & + & - & - & + & + & + & - & - & - & + & + & - & - & - & - & - & - & - & & + & & - \\
\hline Proteus spp & - & - & $+/-$ & - & - & + & $+/-$ & + & - & $+/-$ & $+/-$ & + & $+/-$ & - & - & - & - & $+/-$ & - & - & & + & & - \\
\hline $\begin{array}{l}\text { Pseudomonas } \\
\text { spp }\end{array}$ & - & $+/-$ & - & - & - & - & - & - & - & - & - & + & $+/-$ & - & - & - & - & - & - & - & - & - & & + \\
\hline $\begin{array}{l}\text { Pseudomonas } \\
\text { aeruginosa }\end{array}$ & - & + & - & - & - & - & - & - & - & - & - & + & $+/-$ & - & - & - & - & - & - & - & - & - & & + \\
\hline $\begin{array}{l}\text { Escherichia } \\
\text { coli }\end{array}$ & $+/-$ & $+/-$ & $+/-$ & - & - & - & - & - & + & - & - & + & + & - & - & $+/-$ & - & - & - & $+/-$ & + & + & & - \\
\hline
\end{tabular}

ONPG = Ortho-Nitro-Phenyl-Galactosidase; ADH = Arginine Hydrolase; LDC = Lysine Decarboxylase, ODC = Ornithine Decarboxylase; $\mathrm{CIT}=$ Simmons Citrate; $\mathrm{H} 2 \mathrm{~S}=\mathrm{Dihydrogen}$ sulphide; Urea; TDA = Tryptophan Deaminase; IND = Indole; VP; Vogues-Proskauer; GEL = Gelatine; GLU = Glucose; MAN = Mannitol; INO = Inositol; SOR = Sorbitol; RHA = Rhamnose; SAC = Sucrose; MEL = Melibiose; AMY = Amygdalin; ARA = Arabinose, $\mathrm{COA}$ = Coagulase, $\mathrm{CAT}$ = Catalase; GAL = Galactose; $\mathrm{OX}=$ Oxidase. $\mathrm{NB}$ : empty boxes: these are biochemical tests not carried out. 
Table 6 Morphological and biochemical characteristics of the bacteria isolated

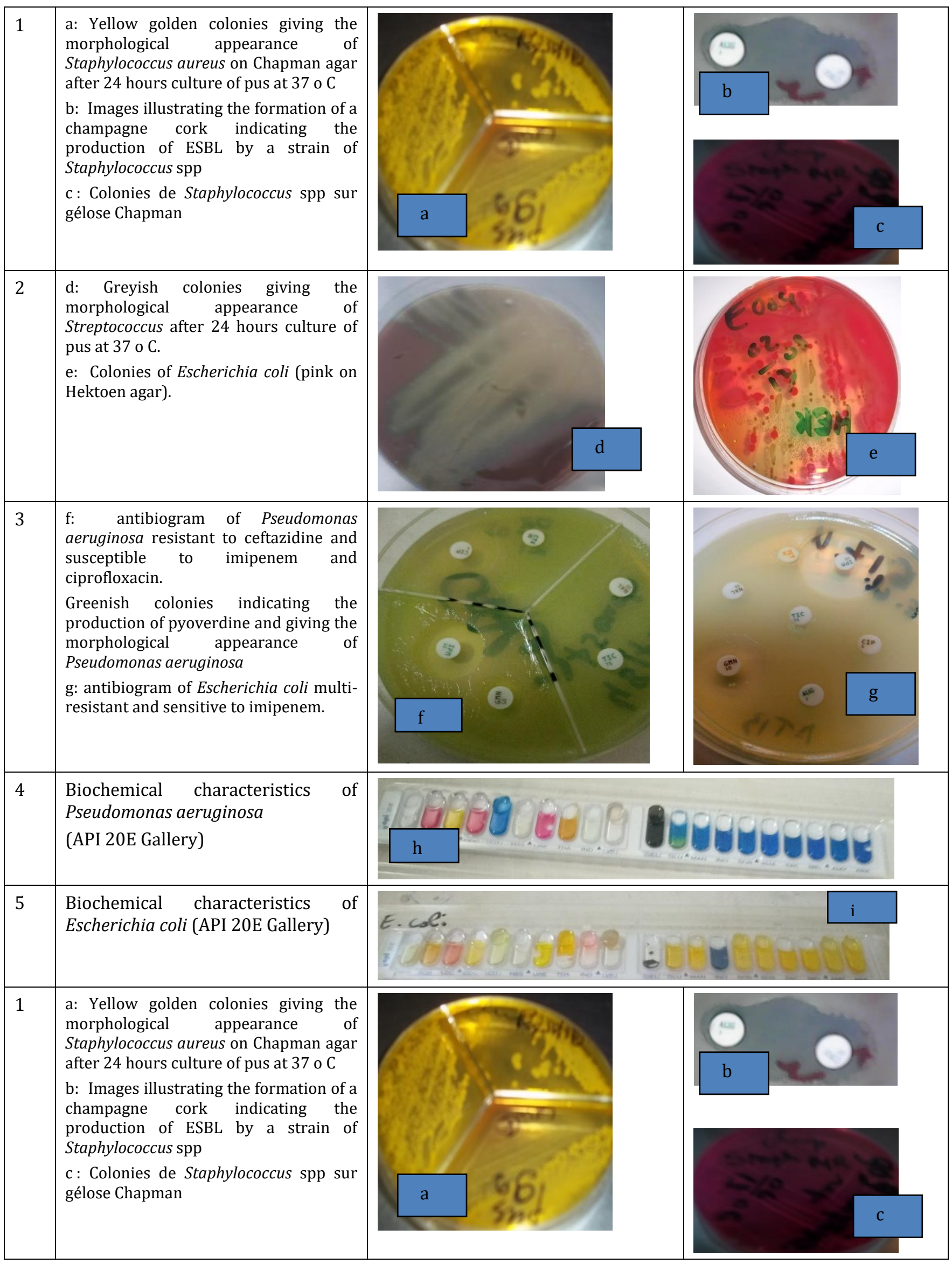




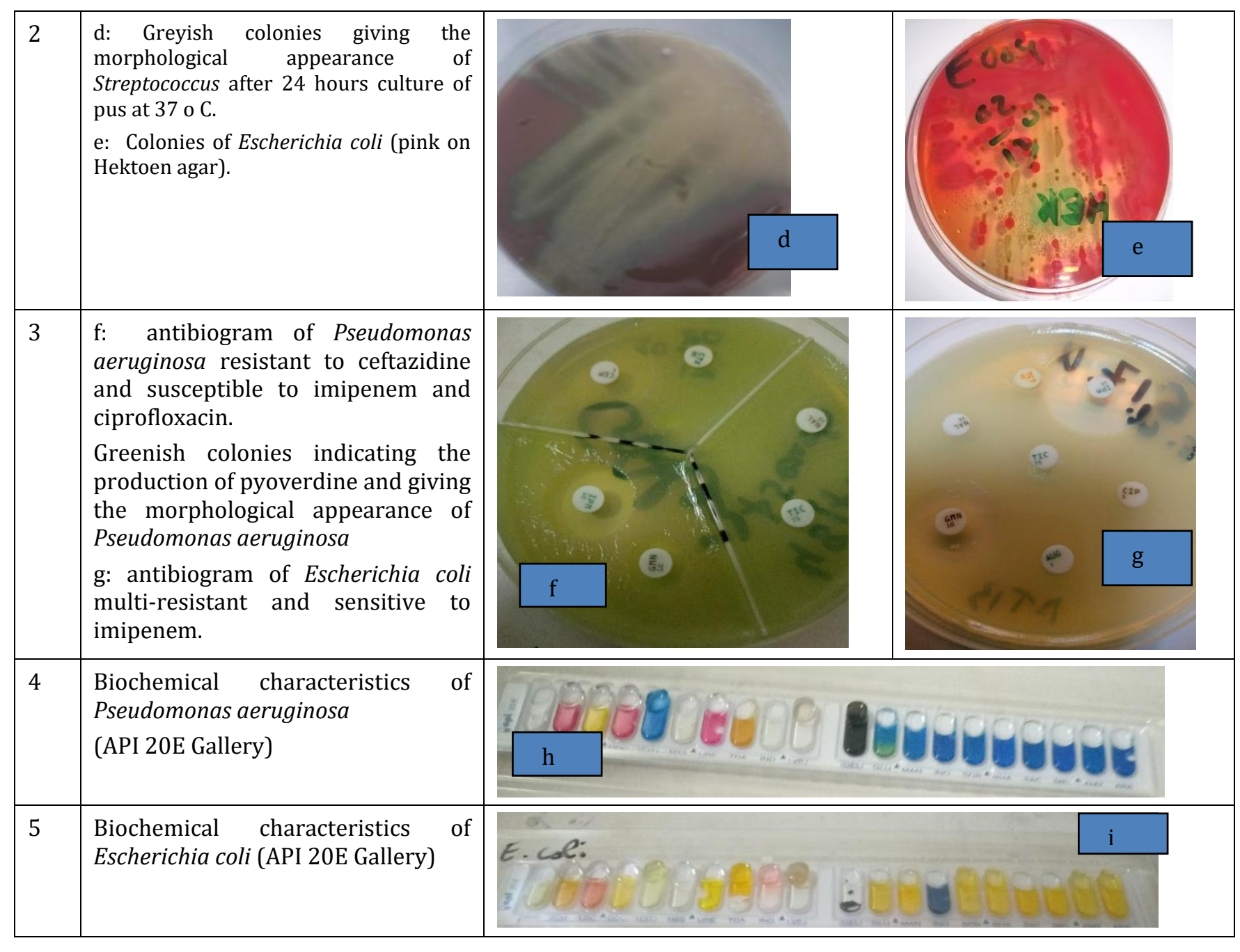

\section{Discussion}

Our study took place at the Bacteriology Unit of the laboratory of the National Reference University Hospital of N'Djamena from August 1, 2018 to August 1, 2019. It was a prospective observational study during which we analyzed 527 pus samples from the sites. Operations from the General Surgery 145 (27.5\%), Urology $211(40 \%)$ and Traumatology 171 (32.5\%) departments.

The study involved the remaining 527 patients. Of the 527 cultures performed 453 were positive (86\%) and 74 cultures were negative (14\%). This high frequency of positive cultures could be explained in part by the promiscuity of patients in the inpatient departments.

The low culture negative rate in this study could be justified by the fact that all operated patients had received antibiotic therapy.

The average age of the patients was 52 with the extremes of 15 to 90 years and $43 \%$ of them belonged to the age group of 20 to 30 years. Our results were comparable to those obtained elsewhere $[4,11,15]$. They were higher than those obtained by Madougou in 2010 in Benin, which had obtained an average age of 40 years out of a sample of 2218 [14].

Age is thought to play a role in the genesis of an infection at the surgical site $[19,18,20]$.

Our results could be explained by the fact that the Chadian population is predominantly young. This age group is the most socio-economically active. She is often the victim of road accidents causing open fractures and wounds. According to the World Health Organization (WHO), road accidents are the leading cause of death among young people aged 15 to 29. [17] 
Male sex was predominant with a sex ratio of 2.29. This result is consistent with the data in the literature. It is higher than that obtained by Bassolé I. in Ouagadougou in 2012. [13] who also found a male predominance with a sex ratio of 1.63 on a sample of 360. It is lower than that of Madougou in Cotonou in Benin in 2010 which obtained a male predominance with a sex ratio of 3.19 out of a sample of 88 [14]. This male predominance could be explained by the difficulty women have in accessing health care. In the literature, opinions are divided. For some authors, gender is a factor influencing the occurrence of ISO $[5,7,8]$.

In contrast, others believe that ISO is more common in women [30].

Our results could also be explained by a high frequency of accidents in men due to their daily activities causing fractures and penetrating wounds. This predominance of SSI on fracture has also been reported by Madougou et al. [14] and by Pivot Diane [16] who found $88.7 \%$ and $75.2 \%$ respectively of fractures.

In our study, the most represented profession was that of pupils / students $(27.7 \%)$ followed by truck drivers with 15.6\%. This result is comparable to that found by Bouare in Mali in 2010 [9] which found 39\% of pupils / students and higher than that of Mariam who found in 2012 in Mali 12.5\% of pupils / student and 25\% civil servants [10]. This difference could be explained by the high number of postoperative complications recorded in this vulnerable age group. This result could also explain the fact that, the pupils / students by going daily to their places of course were often victims of the accidents of the public highway requiring most often surgical interventions.

During our study, the search for the germs responsible for SSI resulted in 453 (86\%) positive cultures and 74 (14\%) sterile cultures: In total, we isolated 453 germs. These results are comparable to that obtained by Ouedraogo in 2011 with $84.4 \%$ positive culture in his study entitled bacteriological profile of surgical site infections at the Souro Sanou University Hospital Center in Bobo-Dioulasso in Burkina Faso [22]. It is superior to those obtained by Faye-kette et al. in Côte d'Ivoire with 70\% in their study entitled Microbial Epidemiology of Surgical Site Infections (SSI) in a trauma service in Abidjan [8]. This result demonstrates that culture remains the key element in the etiological diagnosis of ISOs.

Escherichia coli was the most identified bacterial germ 139 (32.7\%) followed by Staphylococcus spp 89 (20.9\%). These results are comparable to those obtained elsewhere [15]. On the other hand, Katienga in 2012 Burkina Faso found E coli 61.5\% and Pseudomonas aeruginosa 30.7\% [19]. Abdoulaye 0. et al reported during their study entitled Epidemiological and Bacteriological Aspect of Surgical Site Infections in the Surgery Services of the Niamey National Hospital that the S. aureus species was largely in the majority with 31\% [18]. These differences could be explained by the fact that these germs are responsible for infectious hospitalism or nosocomial infection.

The isolates tested showed varying susceptibility to antibiotics. This sensitivity ranged from 33 to $100 \%$ to gentamicin. It ranged from 93.7 to $100 \%$ for imipenem, which is a last resort antibiotic. On the other hand, these isolates showed strong resistance to other antibiotics of the beta-lactam class. This resistance ranged from 0 to $85.9 \%$. This result is comparable to those obtained by Bessimbaye et al. [1] who reported a prevalence of BMR at 66.6\% and ESBL at 33.3\% to beta-lactams during their study on the prevalence of bacterial multi-resistance in a hospital in N'Djamena [1].

Quinolones exhibited varying susceptibility to isolates. This sensitivity varies according to the germs: Staphylococcus aureus was sensitive 27 times out of 37 tests to nalidixic acid (72.9\%), and sensitive 25 times out of 37 tests, or $78.3 \%$ to ciprofloxacin. Escherichia coli was $77 \%$ resistant to nalidixic acid and sensitive to norfloxacin 16 times out of 24 tests, or $66.6 \%$. These results corroborate those of Bassolé in Burkina Faso in 2012 [13], who found a sensitivity of $64.9 \%$ of bacteria to ciproflaxacin.

During our study, Escherichia coli was 100\% susceptible to imipenem. This result is superior to that of Bassolé in Burkina Faso who reported a $95.7 \%$ sensitivity of Escherichia coli to imipenem [13]. However, there was variable resistance in Escherichia coli to other beta-lactams: $73.9 \%$ resistance to penicillin and $71.9 \%$ to ampicillin. This result is comparable to that of Bessimbaye et al. [1] who reported a 64\% resistance of Escherichia coli to beta-lactam. This result could be explained by the fact that these bacteria produce broad-spectrum beta-lactamases which allow them to resist antibiotics.

The antibiotic sensitivity study of strains of Staphylococcus spp showed a sensitivity of $98.8 \%$ to imipenem. Sensitivity of approximately $67.4 \%$ to amoxicillin-acid + clavulanic acid. However, they showed variable resistance to other betalactams: $68.5 \%$ to oxacillin and $66.3 \%$ to penicillin. Bassolé found a sensitivity of $83.3 \%$ of streptococci to penicillin [13]. These variations in resistance of the different bacterial strains isolated towards antibiotics could be explained by the absence of a strategy for prescribing antibiotics, self-medication, ignorance of the problems of resistance to antibiotics which are the direct causes of inactivity of beta-lactams to isolated bacterial strains. 
During our study, 52 strains of Staphylococcus aureus were isolated which showed 100\% susceptibility to imipenem. However, variable resistance of Staphylococcus aureus strains to other beta-lactams has been noted. It was 55.5\% on penicillin and $83.3 \%$ on ampicillin. Bassolé in Burkina Faso [13] reported a sensitivity of 100\% of Staphylococcus aureus strains to imipenem and a sensitivity of $81.8 \%$ to ciproflaxacin. This resistance to beta-lactams could be explained by the production of extended-spectrum beta-lactamases (ESBL) by bacteria.

The sensitivity of Pseudomonas aeruginosa to fluoroquinolones in particular with ciprofloxacin (68\%) and ofloxacin $(63 \%)$ was significant in this study, thus revealing their power against pathogens. However, widespread use can lead to resistance to fluoroquinolones [1].

In this study, Pseudomonas aeruginosa showed high resistance to nitrofurantoin (79\%), which contrasts with a report that nitrofurantoin is a urinary antiseptic and has better sensitivity and is considered safe by some authors [21]. Pseudomonas aeruginosa is widely known for its high rate of resistance and has been reported for this unique ability of intrinsic and extrinsic resistance to drugs commonly used for antimicrobial chemotherapy [24, 25]. This situation is very worrying because it has been confirmed by several studies which have linked multidrug resistance and increased morbidity and mortality [27, 30]. According to the results of this study, all Pseudomonas aeruginosa isolated from operated patients were resistant to multiple antibiotics. This high prevalence of multiple antibiotic resistance (MAR) is alarming and in line with the conclusions of previous researchers [26,28]. Resistivity of isolates to various antibiotics could be due to overuse of antibiotics and self-medication resulting in drug resistance, in particular by Pseudomonas aeruginosa [29].

\section{Conclusion}

Surgical site infections are frequent complications in surgery and cause morbidity and death. During our study, we analyzed 527 samples and 453 cultures were positive (86\%). ISOs affect young populations much more, with a predominance of men. The etiology of SSIs is dominated by germs, most often bacterial.

Probabilistic antibiotic therapy, self-medication, the use of antibiotics at inappropriate doses lead to the selection and maintenance of multi-resistant strains in hospital settings. The cytobacteriological examination of the pus allowed us to identify the responsible germs, the most frequent of which were Escherichia coli followed by Staphylococcus spp which is increasingly resistant to antibiotics.

The antibiotic most sensitive to the isolated organisms was imipenem with a sensitivity ranging from 93.7 to $100 \%$ to isolates. The isolates as a whole showed marked resistance to beta-lactams.

\section{Compliance with ethical standards}

\section{Acknowledgments}

We thank the Dean of the Faculty of Human Health Sciences (FSSH) of the University of N'Djamena and the Director of the National Reference University Hospital (CHU-RN) for authorizing this research. Our thanks also go to the patients who agreed to participate in this study.

\section{Disclosure of conflict of interest}

The authors declare that they have no conflict of interest.

\section{References}

[1] Bessimbaye N, Abdelsalam T, Ndoutamia G, Kerah HC, Barro N. Prevalence of Multi-Resistant Bacteria in Hospital N'djamena, Chad. Chemotherapy. 2015; 4 (4): 1-6.

[2] Brun-Buisson. Les infections nosocomiales, bilan et perspectives. Revue-médecine/ science/ Paris . 2000; 16: 8902 .

[3] Traoré B. Complications infectieuses en Chirurgie abdominale à propos de 369 cas. [Thèse de Médecine]. Mali : Université de Bamako. 1993. 
[4] Doumbia G. Morbidité et mortalité observée dans un service de chirurgie générale de Centre Hospitalier Universitaire de Treichville : Guide Technique d'Hygiène Hospitalière 2004. Comité de Lutte contre les Infections Nosocomiales Sud Est. 1983; 633(2.02): 6.

[5] Camara E. Etude Prospective de l'anti bio prophylaxie sur un an au centre de traumatologie, d'orthopédie et de rééducation fonctionnelle de Dakar. Médecine Noire. 1992; 39(10): 701-04.

[6] Olivia L, Julie-Hélène F, Marie A. Comment utiliser l'antibiogramme afin de faire un meilleur usage des antibiotiques? Conférence AVIA. 15 mai 2018; 19.

[7] Ngaroua N, Joseph E, Thomas B, Yaouba D. Incidence des infections du site opératoire en Afrique sub-saharienne : revue systématique et méta-analyse. Pan African Journal. 2016; 24: 171-79.

[8] Faye-Kette H, Kouassi MY, Akoua-Koffi G, Bakayoko S, Boni C, Diallo TK. Epidémiologie microbienne des Infections de Sites Opératoires (ISO) dans un service de Traumatologie à Abidjan et sensibilité des germes aux antibiotiques. Revue Bio-Africa. 2008; (6): 25-31.

[9] Bouare Y-M. Infections postopératoires dans le service de Traumato-Neurologie du CHU Gabriel Touré Thèse médecine, Bamako. 2010; 87: n²37

[10] Mariam Yama Bouaré. Etude des infections postopératoires dans le Service de Traumato-Neurochirurgie de l'Hôpital Gabriel Touré du Mali [Thèse de Médecine]. Mali : Université de Bamako. 2010.

[11] Ouédraogo AS, Somé DA, Dakouré PWH, Sanon BG, Birba E, Poda GEA. Profil bactériologique des infections du site opératoire au Centre Hospitalier Universitaire Souro Sanou de Bobo Dioulasso. Médecine Tropicale. 2011; 71: 1-4.

[12] Lozwniewski A, Rabaud C, Nancy. Résistance bactérienne aux antibiotiques. CCLIN Sud-Est. 2010.

[13] Bassolé I. Profil bactériologique des suppurations post opératoires dans les Services de Chirurgie Digestives et Traumatologiques du Centre Hospitalier Universitaire de Yalgado Ouedraogo du 1er août 2010 au 30 juillet 2011. [Thèse de Médecine]. Burkina Faso : Université de Ouagadougou. 2012.

[14] Madougou S, Tchomtchoua AS, Gandaho H, Essoun S. Mesure de l'infection de site opératoire après ostéosynthèse par enclouage centromédullaire du fémur et du tibia au CNHU de Cotonou au Benin. Le Bénin Médical. 2010; 44: 1-4.

[15] Laouli B, Aspect épidémiologique et bactériologique des infections du site opératoire dans les Services de Chirurgie de l'Hôpital National de Niamey. Pan African journal Medical. 2018; 31: 33.

[16] Pivot Diane. Élaboration d'un système automatisé d'aide à la détection des infections du site opératoire au centre hospitalo-universitaire régional de Nancy : étude pilote. $2015 ; 30$.

[17] OMS, Principaux repères sur les accidents de la route.

[18] Abdoulaye 0, Harouna AM, Oumarou A, Harouna ML, Laouli B. Aspect épidémiologique et bactériologique des infections du site opératoire dans les Services de Chirurgie de l'Hôpital National de Niamey. Pan African journal Medical. 2018; 31(33): 1-6.

[19] Katienga S Judith. Les infections du site opératoire: Aspect épidémiologique, clinique, bactériologique et thérapeutiques dans les services de chirurgie viscérale du CHUYO. A propos de 55 Cas. Thèse de pharmacie. 2012.

[20] Mahmoud AB, Zahran WA, Hindawi GR, Labib A Z, Galal R. Prevalence of Multidrug-Resistant Pseudomonas aeruginosa in Patients with Nosocomial Infections at a University Hospital in Egypt, with Special Reference to Typing Methods. IBIMA Publishing Journal of Virology and Microbiology. 2013; 1-13.

[21] Meletis G and Bagkeri M. Pseudomonas aeruginosa: Multi-Drug-Resistance. Development and Treatment Options. Infection control In Techogy. 2013; 33-56.

[22] Ouédraogo AS, Somé DA, Dakouré PWH, Sanon BG, Birba E, PodaGEA et al. Profil bactériologique des infections du site opératoire au Centre Hospitalier Universitaire Souro Sanou de Bobo Dioulasso. Médecine Tropicale. 2011; (71): 4.

[23] Choua O, Kimassoum R, Ngueidjo Y, Kalli M, Mignagnal K. Aspects des traumatismes fermés de l'abdomen opérés à l'Hôpital Général de Référence Nationale de N'Djaména (HGRN), Tchad : à propos de 49 cas. The pan African Journal. 2017; 26(50): 1-6.

[24] Meletis G, Bagkeri M. Pseudomonas aeruginosa: Multi-Drug-Resistance. Development and Treatment Options. Infection control In Techogy. 2013; 33-56. 
[25] Poole K. Pseudomonas aeruginosa: Resistance to the max. Frontiers in Microbiology. 2011; 2: 65.

[26] Sabharwal, ER. Antibiotic Susceptibility Patterns of Uropathogens in Obstetric Patients. American Journal of Medical Science. 2012; 4: 316-319.

[27] Tumbarello M, Repetto E, Trecarichi EM, Bernardini C, De Pascale G, Parisini A, Rossi M, Molinari MP, Spanu T, Viscoli C, Cauda R, Bassetti M. Multidrug-resistant Pseudomonas aeruginosa bloodstream infections: riskfactors and mortality. Epidemiology and Infection. 2011; 139: 1740-49.

[28] Nordmann P, Boulanger AE, Poirel L. NDM-4 Metallo-B-Lactamase with Increased Carbapenemase Activity from Escherichia coli. Antimicrobial Agents of Chemotherapy. 2012; 56(4): 2184-86.

[29] Mahmoud, AB, Zahran WA, Hindawi GR, Labib A Z, Galal R. Prevalence of Multidrug-Resistant Pseudomonas aeruginosa in Patients with Nosocomial Infections at a University Hospital in Egypt, with Special Reference to Typing Methods. IBIMA Publishing. Journal of Virology and Microbiology. 2013; 1-13.

[30] Mauldin PD, Salgado CD, Hansen IS, Durup DT, Bosso JA. Attributable Hospital Cost and Length of Stay Associated with Health Care associated Infections Caused by Antibiotic-resistant Gram- negative Bacteria. Antimicrobial Agents and Chemotherapy. 2012; 54: 109-15. 